\title{
Mature cystic teratoma of the fallopian tube associated with incomplete uterine mediastinum: A case report and literature review
}

\author{
SHUYI LI, XIAOLING FANG, JIANLIN CHEN and XIAOMENG XIA \\ Department of Obstetrics and Gynaecology, The Second Xiangya Hospital, \\ Central South University, Changsha, Hunan 410000, P.R. China \\ Received January 17, 2013; Accepted May 14, 2013
}

DOI: $10.3892 / 01.2013 .1355$

\begin{abstract}
Neoplasms of the fallopian tube are extremely uncommon. In addition, the incidence of a mature teratoma of the fallopian tube with incomplete uterine mediastinum is extremely low. In the current case report, we present a case of mature cystic teratoma of the fallopian tube with incomplete uterine mediastinum in a 23 -year-old female. This mass was noted on computed tomography (CT) scan and sonographic examination. The patient underwent left salpingectomy and uterine septum incision during surgery. One year later, the individual became pregnant.
\end{abstract}

\section{Introduction}

Neoplasms of the fallopian tube are the least common tumors of the female reproductive system. To date, mature teratoma of the fallopian tube associated with incomplete uterine mediastinum has not been reported and $\sim 60$ cases of mature teratoma of the fallopian tube have been reported worldwide. None of the reported cases were diagnosed preoperatively. The pathogenesis of teratoma of the fallopian tube remains poorly understood. Tumors are accidentally discovered and confirmed by pelvic surgery, as a result of diagnosis of uterine fibroids, ovarian cysts and cesarean sections. It has been hypothesized that teratomas originate from the germ cells, as teratomas are found most frequently in the gonads. The karyotype of all benign teratomas is 46,XX. Surgery is used to treat teratomas and the prognosis of this disease is generally good (1-5). In the present case report, the patient was presented to The Second Xiangya Hospital of Central

Correspondence to: Professor Xiaoling Fang, Department of Obstetrics and Gynaecology, The Second Xiangya Hospital, Central South University, 139 Renmin Road, Changsha, Hunan 410000, P.R. China

E-mail: fxlfx10510@126.com

Key words: teratoma, fallopian tube, infertility, incomplete uterine mediastinum
South University (Changsha, China) with fertility issues. The postoperative diagnosis was incomplete uterine mediastinum and mature cystic teratoma of the fallopian tube. One year after surgery, the patient became pregnant and gave birth to a healthy baby. Written informed consent was obtained from the patient.

\section{Case report}

Patient presentation. A 23 -year-old female (gravida 0 , para 0 ) who had been married for two years was admitted to The Second Xiangya Hospital of Central South University (Changsha, China) with fertility issues. The patient reported intermittent lower abdominal pain for 8 months. The individual's menstrual cycle was regular. Pelvic examination revealed a stationary cystic mass of $\sim 8 x 3 \mathrm{~cm}$ in the left adnexal region; the right adnexa and the uterus were normal. The patient's family history was negative for any hereditary diseases. Serum concentrations of $\mathrm{C} 12$ were within the normal limits. Ultrasound examination revealed that the endometrium was unclear, and a cystic mass of $\sim 8 \times 4 \mathrm{~cm}$ to the right of hypogastic region was observed. The mass contained foci of calcification of $\sim 3 \times 2 \mathrm{~cm}$ (Figs. 1 and 2). A pelvic computed tomography $(\mathrm{CT})$ scan revealed a $6 \times 4.5 \mathrm{~cm}$ cystic mass in the left pelvis, which was suspected to represent a cystic teratoma of the left ovary (Fig. 3). The density of the uterine body was irregular as shown by enhanced B sonography, which did not eliminate the presence of uterine disease.

Surgical procedures. The patient underwent surgery with a diagnosis of cystic teratoma of the left ovary, incomplete uterine mediastinum and infertility. At the time of surgery, incomplete mediastinum $(\sim 2 \mathrm{~mm})$ was observed at the bottom of the uterus. The left fallopian tube appeared to be distended by $\sim 8 \times 3 \mathrm{~cm}$, and contained cream-colored sebaceous material and hair. The left ovary and the right adnexa were normal. The patient subsequently underwent left salpingectomy and uterine septum incision. The post-operative recovery was uneventful. The ampullary portion of the left fallopian tube was histologically diagnosed as mature cystic teratoma (Figs. 4 and 5). 
Table I. Tubal teratomas in the literature.

\begin{tabular}{|c|c|c|c|c|c|c|}
\hline First author (ref.) & Complication & Age, years & $\begin{array}{l}\text { Gravidity }{ }^{\mathrm{a}} \\
\text { and parity }\end{array}$ & Side & Size, $\mathrm{cm}$ & Other \\
\hline Baginski & Ectopic pregnancy & 33 & $\mathrm{G} 2 \mathrm{P} 2$ & $\mathrm{~L}$ & Egg & Increased hCG \\
\hline Roberts & Ectopic pregnancy & 29 & G0P0 & $\mathrm{L}$ & $4 \times 2$ & Increased hCG \\
\hline Neumann & Ectopic pregnancy & 36 & G0P0 & $\mathrm{L}$ & $3.4 \times 1$ & Increased hCG \\
\hline Zelinger & Ectopic pregnancy & 30 & $\mathrm{G} 2 \mathrm{P} 2$ & $\mathrm{~L}$ & $1 \times 1.5$ & Increased hCG \\
\hline Massouda & Ectopic pregnancy & 24 & G0P0 & $\mathrm{R}$ & $2.5 \times 1$ & Increased hCG \\
\hline Kutteh & Ectopic pregnancy & 25 & G3P3 & $\mathrm{L}$ & $2 \times 2$ & Increased hCG \\
\hline Chao & Uterine leiomyomatosis & 40 & G6P2 & $\mathrm{L}$ & $4.0 \times 2.2 \times 1.2$ & Normal C12 \\
\hline Hoda & Struma salpingis & 44 & & $\mathrm{~L}$ & 0.2 & $\begin{array}{l}\text { A } 7.0-\mathrm{cm} \text { mucinous } \\
\text { cystadenoma of the } \\
\text { contralateral ovary }\end{array}$ \\
\hline Roncati & $\begin{array}{l}\text { Endometrial } \\
\text { adenocarcinoma }\end{array}$ & 67 & G4P4 & $\mathrm{L}$ & $0.5 \times 0.6$ & \\
\hline $\mathrm{PC}$ & $\begin{array}{l}\text { Incomplete uterine } \\
\text { mediastinum }\end{array}$ & 23 & G0P0 & $\mathrm{L}$ & $8 \times 3$ & Normal C12 \\
\hline
\end{tabular}

${ }^{\mathrm{a}}$ Gravidity does not include the ectopic gestation at the time of presentation. PC, present case; G, gravidity; P, parity; L, left; R, right.

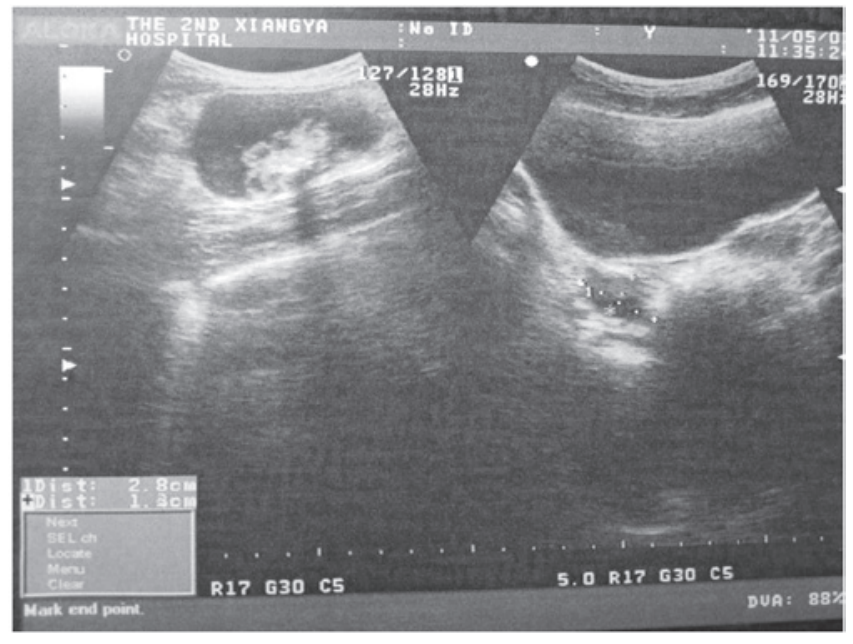

Figure 1. Sonographic examination of the pelvis revealed a cystic mass of $\sim 8 \times 4 \mathrm{~cm}$ in the right hypogastic region.

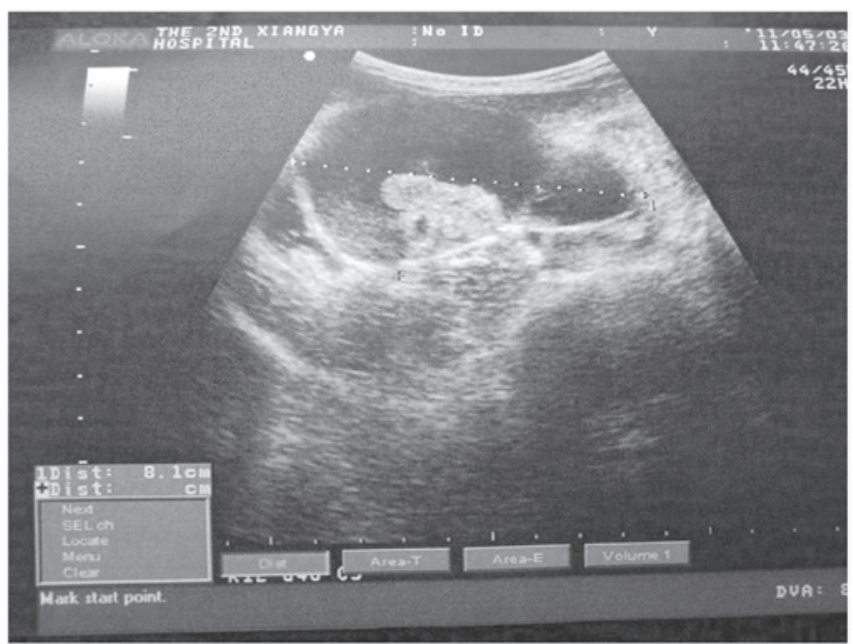

Figure 2. Sonographic examination of the pelvis revealed that the mass contained foci of calcification of $\sim 3 \times 2 \mathrm{~cm}$.

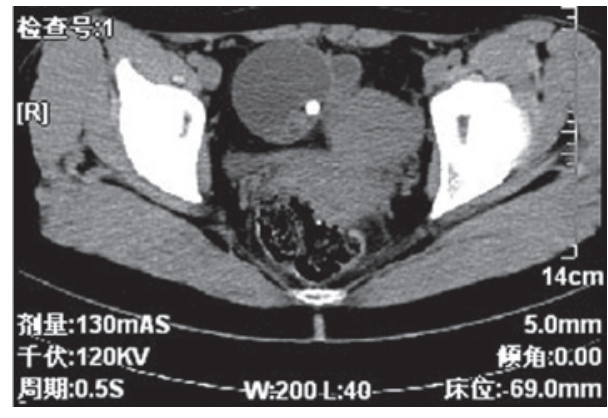

Figure 3. Pelvic computed tomography (CT) scan revealed a $6 \times 4.5 \mathrm{~cm}$ cystic mass to the left of pelvis.

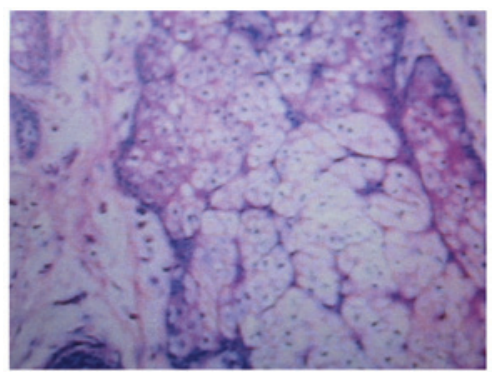

Figure 4. Microscopic observations of the mature teratoma demonstrate a cyst lined entirely by well-differentiated keratin-producing squamous epithelium (magnification, x100).

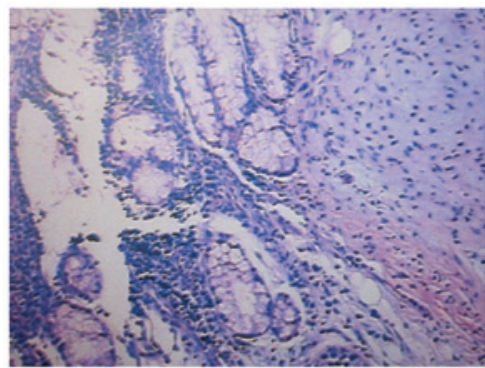

Figure 5. Microscopic mature teratoma observations (magnification, x100). 


\section{Discussion}

Tubal teratoma may be associated with other neoplasms $(6,7)$, struma ovarii, ectopic pregnancy $(8,9)$, uterine leiomyomatosis (10) and endometrial adenocarcinoma (11) (Table I). The present case study is the first in the literature to report a mature cystic teratoma of the fallopian tube associated with incomplete uterine mediastinum (11). In addition, the teratoma in the present case was the largest of all reported cases of mature cystic teratomas of the fallopian tube. The diversity of teratoma behavior is likely to reflect the varied biological potential of different stem cells, including germ and pluripotent embryonic cells. Benign teratoma of the fallopian tube is composed of tissues of ectodermal, mesodermal and endodermal origin in any combination (1). Teratomas are initially of mesodermal origin with abundant mesenchymal stroma; however, it eventually develops endodermal and ectodermal derivatives with airway-lining enterocytes, thyroid, brain and skin appendages (12). The majority of cases of benign teratoma of the fallopian tube occur in patients in their 40s and are cystic and exhibit significant variations in size. The majority of benign teratomas of the fallopian tube are unilateral and are common in $1 / 3$ of the fallopian tube or the outer edge of the fallopian tube. The tumors tend to be small and contain sebum-like material with hairs. Fallopian tube teratomas have been associated with reduced parity, menstrual irregularity, leukorrhea, post-menopausal bleeding and abdominal pain. Procedures, including analysis of serum C12 levels, pelvic CT scan, ultrasound examination (13) and hysterosalpingography (12), are useful for diagnosis. The prognosis of the disease is good. In the present case, the patient was 23 years-old; however, the teratoma was larger compared with other studies (14-19). The majority of tubal teratomas are benign. In the current case, the patient suffered from incomplete uterine mediastinum, which was due to paramesonephric duct convergence insufficiency. Intermittent lower abdominal pain has been reported in other cases, consistent with the current case; however, the patient was originally admitted to hospital due to infertility. One year following the surgery, the individual became pregnant.

In conclusion, benign teratomas commonly occur in the ovaries, but are rarely found in the fallopian tubes. Although the present case was a cystic teratoma, immature tissues were not identified by microscopic examination of the specimens by several pathologists. Therefore, a diagnosis of a benign mature cystic teratoma originating in the fallopian tube was reported for this patient.

\section{References}

1. Mutter GL: Teratoma genetics and stem cells: a review. Obstet Gynecol Surv 42: 661-670, 1987.

2. Norris HJ, Zir HJ and Barson WL: Immature (malignant) teratoma of the ovary: a clinical and pathologic study of 58 cases. Cancer 37: 2359-2372, 1976.

3. Corfman PA and Richart RM: Chromosome number and morphology of benign cystic teratoma. N Engl J Med 271: 1241-1244, 1964.

4. Rashad MN, Fathalla RM and Kerr MG: Sex chromatin and chromosome analysis in ovarian teratomas. Am J Obstet Gynecol 96: 461-465, 1966

5. Linder D, McCaw BK and Hecht F: Pathogenic origin of benign ovarian teratoma. N Engl J Med 292: 63-66, 1975.

6. Hoda SA and Huvos AG: Struma salpingis associated with struma ovarii. Am J Surg Pathol 17: 1187-1189, 1993.

7. Mazzarella P, Okagaki T and Richart RM: Teratoma of the uterine tube. Obstet Gynecol 39: 381-388, 1972.

8. Pai MR, Naik R and Baliga P: Mature cystic teratoma of the fallopian tube associated with ectopic pregnancy. J Indian Med Assoc 95: 88, 1997.

9. Kutteh WH and Albert T: Mature cystic teratoma of the fallopian tube associated with an ectopic pregnancy. Obstet Gynecol 78: 984-986, 1991.

10. Chao TJ, Chao J, Kuan LJ, Li YT, Kuo TC, Chang YC and Nieh S: Mature solid teratoma of the fallopian tube associated with uterine leiomyomas. J Chin Med Assoc 71: 425-427, 2008.

11. Roncati L, Barbolini G, Ghirardini G and Rivasi F: Mature solid teratoma of the fallopian tube mimicking metastasis of endometrial adenocarcinoma: a case report. Int J Surg Pathol 18: 561-563, 2010.

12. Fujiwara S, Yamashita Y, Yoshida Y, Terai Y, Okuda K and Ohmichi M: Mature cystic teratoma of the fallopian tube. Fertil Steril 94: 2708-2709, 2010.

13. Johnson $\mathrm{C}$ and Hansen KA: Mature cystic teratoma of the fallopian tube. Fertil Steril 86: 995-996, 2006.

14. Yoshioka T and Tanaka T: Mature solid teratoma of the fallopian tube: case report. Eur J Obstet Gynecol Reprod Biol 89: 205-206, 2000.

15. Baginski L, Tazigi R, Sandstad J. Immature (malignant) teratoma of the fallopian tube. Am J Obstet Gynecol 160: 671-672, 1989.

16. Roberts D: A case of ectopic gestation removal, by abdominal section with a dermoid tumor of the extremity of the left tube. Lancet 2: 1164-1165, 1903.

17. Neumann HO: Teratoma der tube. Arch Gynaekol 130: 766-774, 1927 (In German).

18. Zelinger BB, Grinvalsky HT and Fields C: Simultaneous dermoid cyst of the tube and ectopic pregnancy. Obstet Gynecol 15: 340-343, 1960.

19. Massouda D, Wortham GF III and Oakley JL. Tubal pregnancy associated with a benign cystic teratoma of the fallopian tube. A case report. J Reprod Med 33: 563-564, 1988. 